NBER WORKING PAPER SERIES

\title{
INNOVATIVITY: A COMPARISON ACROSS SEVEN EUROPEAN COUNTRIES
}

\author{
Pierre Mohnen \\ Jacques Mairesse \\ Marcel Dagenais \\ Working Paper 12280 \\ http://www.nber.org/papers/w12280 \\ NATIONAL BUREAU OF ECONOMIC RESEARCH \\ 1050 Massachusetts Avenue \\ Cambridge, MA 02138 \\ May 2006
}

We have benefitted from useful comments by Elena Bontempi, Christian Debresson, Dominique Guellec, Emmanuel Duguet, Nathalie Greenan and Petr Hanel. We thank particularly Bronwyn Hall for helpful suggestions and a careful rereading of a (nearly) final version of the study. We are grateful to Eurostat for providing, and giving us permission to use, the micro-aggregated CIS1 firm data. We also acknowledge research assistance of Julio Rosa and financial support by Industry Canada, OECD, SSHRC and CNRS. A summary account of some of the results of this study can be found in Mairesse and Mohnen $(2001,2002)$. Note that what we called innovativeness in these two papers, we choose to name here more simply "innovativity". Marcel Dagenais passed away before this paper was completed. He could not read and correct the last versions of it. The paper bears his input. We hope it also bears his standards. The views expressed herein are those of the author(s) and do not necessarily reflect the views of the National Bureau of Economic Research.

(C)2006 by Pierre Mohnen, Jacques Mairesse and Marcel Dagenais. All rights reserved. Short sections of text, not to exceed two paragraphs, may be quoted without explicit permission provided that full credit, including (C) notice, is given to the source. 
Innovativity: A Comparison Across Seven European Countries

Pierre Mohnen, Jacques Mairesse and Marcel Dagenais

NBER Working Paper No. 12280

May 2006

JEL No. C35, L60, O31, O33

\begin{abstract}
$\underline{\text { ABSTRACT }}$
This paper proposes a framework to account for innovation similar to the usual accounting framework in production analysis and a measure of innovativity comparable to that of total factor productivity. This innovation accounting framework is illustrated using micro-aggregated firm data from the first Community Innovation Surveys (CIS1) for seven European countries: Belgium, Denmark, Ireland, Germany, the Netherlands, Norway and Italy for the year 1992. Based on the estimation of a generalized Tobit model and measuring innovation as the share of total sales due to improved or new products, it compares the propensity to innovate, and the innovation intensity conditional and unconditional on being innovative, across the seven countries and low- and high-tech manufacturing sectors. Even with relatively few explanatory variables our innovation framework already accounts for sizeable differences in country innovation intensity. It also shows that differences in innovativity across countries can be nonetheless very large.
\end{abstract}

Jacques Mairesse

INSEE, CREST

15, Boulevard Gabriel PERI

92245 MALAKOFF CEDEX

FRANCE

and NBER

$\underline{\text { mairesse@ensae.fr }}$ 


\section{INTRODUCTION}

Industrial countries have reached a stage of economic development that many describe as "the knowledge-based economy" (KBE). The concept of a KBE is appealing, but its definition is far from being clear-cut. Some say that what distinguishes a KBE from the past industrial economies is that growth is driven less by investments in buildings and equipment than by the generation of ideas and the accumulation of knowledge (see for example Aghion-Howitt, 1998; Foray, 2004; Neef, 1998). Others characterize a KBE by the importance of information and communication technologies, skilled labor, continuous learning, and globalization (see for example Quah, 2001). Whatever definition one comes up with, innovation is certainly one of the pillars of the knowledge-based economy. Competition among firms to attract customers is fought more and more via improved products, entirely new products or more efficient ways to produce existing products.

How to measure innovation? So far, most of the work on science and technology indicators has been based on $\mathrm{R} \& \mathrm{D}$, patent or bibliometric data. $\mathrm{R} \& \mathrm{D}$ data have been collected in a systematic fashion in OECD countries since the inception of the Frascati Manual (OECD, 1963). Patent grants have been recorded by patent offices around the world for a much longer time. Bibliometric data are also widely available in the form of publications and citations, or innovation announcements. All of these indicators have their shortcomings. R\&D measures only research input with no guarantee that the research eventually leads to a marketable and appropriable innovation output. Most patents are worth little and the propensity to patent varies widely across sectors. Bibliometric data are not always collected systematically or readily available, and they suffer even more than patents from the absence of any associated value. It is only recently 
that, under the guidelines of the Oslo Manual (OECD (1992), statistical agencies have started conducting surveys directly asking firms about their innovations. ${ }^{1}$ In these surveys, firms are asked to give information about the inputs, the outputs and the behavioral and organizational dimensions of their innovative activities. On the input side, we have data on $R \& D$ expenditures and on current innovation expenditures besides $R \& D$ (such as the acquisition of patents and licenses, product design, trial production, and market analysis). On the output side, we have the declaration of whether an enterprise has introduced a new product or process and the shares of sales due to incrementally, significantly changed, or entirely new products, which can be new to the enterprise or new to the market. As other dimensions of innovative activities, we have indicators of whether $\mathrm{R} \& \mathrm{D}$ is done on a continuous basis and/or in cooperation with others, and categorical data on the sources of knowledge, the reasons for innovating, the perceived obstacles to innovation, and the perceived strength of various appropriability mechanisms.

In this paper, we take advantage of the first round of harmonized innovation surveys conducted in Europe under the auspices of the Statistical Office of the European

\footnotetext{
${ }^{1}$ There have been a number of more or less similar surveys conducted earlier, focusing on particular aspects of firm innovation process. Probably the best known are the one conducted by the Science and Policy Research Unit (SPRU) of the University of Sussex, which combined information on specific innovations obtained from firms and from a panel of experts, the Yale survey on appropriability, and more recently the Carnegie-Mellon survey. See for example Robson, Townsend and Pavitt (1988), and Geroski, Van Reenen and Walters (1997) for analyses based on the SPRU innovation data; Levin, Klevorick, Nelson and Winter (1987) and Cockburn and Griliches (1988) for analyses based on the Yale survey data; Cohen, Nelson and Walsh (2000) and Arora, Ceccagnoli and Cohen (2003) for analyses based on the Carnegie-Mellon survey.
} 
Community (Eurostat), the so called CIS1 surveys (for first Community Innovation Surveys) covering the years 1990-1992. More precisely, we try to compare the innovation performance for seven European countries: Belgium, Denmark, Germany, Ireland, Italy, the Netherlands and Norway, based on the CIS1 micro-aggregated firm data, as assembled and harmonized by Eurostat. In an exploratory paper, Mohnen and Dagenais (2001) compared the innovation performance of Denmark and Ireland. In the present analysis, we could not consider France because the CIS1 micro-aggregated data available for France did not include the variable on R\&D expenditures. We also excluded Portugal and Greece because their sample was not representative of the whole population but only of innovating firms. Although the original data are firm data, Eurostat was entitled to make them available only in micro-aggregated form for reasons of statistical confidentiality.

"Micro-aggregation" is one among various methods to protect confidentiality. It is a particularly simple and effective way to control for disclosure by adding "error terms" to the raw micro-data, making it extremely difficult, if not fully impossible, to break the anonymity of the individual firm (or more generally statistical unit) surveyed and find out its identity, while preserving "most" of the information useful for statistical analysis. In micro-aggregation methods, the error terms are not defined explicitly but included implicitly in the procedure. The procedure used by Eurostat for CIS1 is micro-aggregation by individual variable ranking (and groups of three observations). It is the following: for any given (continuous) quantitative variable, all firms are first allocated into groups of three on the basis of their ranking by increasing values of the variable; the (simple) arithmetic averages of the variable are then computed for all groups (i.e. over the three 
firms of each group); and finally the raw values of the variable are replaced for all the firms by the corresponding average values. This amounts to adding to every (continuous) variable, for a given firm (i), an error term $\left(\varepsilon_{i}\right)$ equal to the difference between the average value of the variable $\left(\overline{y_{i}}\right)$ for the group of three firms $(i, j$ and $k)$ in which this firm is allocated and its individual value $\left(y_{i}\right) .{ }^{2}$ The procedure is similar for the (discrete) qualitative variables (for more details see Eurostat, 1996 and 1997). Note that microaggregation is a sense a misnomer, since the number of observations (firms) is the same in the micro-aggregated and the raw samples. One great advantage of micro-aggregation is that the error terms added to the variables behave differently than the classical random measurement errors in variables; they are not a source of bias in the estimation of linear regression models for large enough samples. On the basis of the raw firm data of the French CIS2 innovation survey and the corresponding micro-aggregated data, we have also been able to show that the estimates of a non-linear model similar to the one performed here were not sensitive to the micro-aggregation procedure (see Mairesse and Mohnen, 2001). ${ }^{3}$

\footnotetext{
${ }^{2}$ If $i, j$ and $k$ denote respectively the index of the three firms of a given group, when firms are ranked in increasing order of the variable $\mathrm{y}$, we can write equivalently $\overline{y_{i}}=\overline{y_{j}}=\overline{y_{k}}=\left(y_{i}+y_{j}+y_{k}\right) / 3$ or $\overline{y_{i}}=y_{i}+\varepsilon_{i}$ with $\varepsilon_{i}=\left[\left(y_{j}-y_{i}\right)+\left(y_{k}-y_{i}\right)\right] / 3$, $\overline{y_{j}}=y_{j}+\varepsilon_{j}$ with $\varepsilon_{j}=\left[\left(y_{i}-y_{j}\right)+\left(y_{k}-y_{j}\right)\right] / 3$ and $\overline{y_{k}}=y_{k}+\varepsilon_{k}$ with $\varepsilon_{k}=\left[\left(y_{i}-y_{k}\right)+\left(y_{j}-y_{k}\right)\right] / 3$. ${ }^{3}$ See also Hu and Debresson (1998).
} 
Besides contributing to the analysis of the information provided by innovation surveys, and possibly to the improvement in their design, our main purpose in this paper is to organize our thinking on measurement and comparison of innovation performance, and to do so we propose and illustrate the idea of an accounting framework for innovation similar to the now standard production (or output growth or productivity) accounting framework. In this framework, the production of a country, an industry or a firm can be traced back to the use of various factors of production and to other omitted, unobserved, unknown or "residual" factors that are subsumed under the name of total factor productivity, or multifactor productivity, or even simply productivity. Similarly, innovation can be regarded as deriving in part from traceable factors such as R\&D efforts, and from contextual variables such as demand pull and technology push indicators, and in part from yet-to-be-understood unmeasured factors that we propose to identify jointly as total or multifactor innovative productivity, and to call "innovativity" for short. Total factor productivity is generally considered as a measure of productive performance controlling for a given set of factors of production, as well as a measure of our ignorance in accounting fully for this performance. Likewise, innovativity can be viewed as both a measure of innovative performance and a measure of our ignorance in matters of innovation.

The production accounting framework is generally applied to comparisons in the time dimension (i.e. between periods) of output or productivity performances of the unit (or units) under analysis, but it can also be extended to the comparison of such performances in the cross-sectional or spatial dimension, that is between units (in a given period). Similarly, the innovation accounting framework can be applied to either the time 
or the cross-sectional dimension. We shall illustrate it here by comparing innovation in seven European countries in high-tech and low-tech manufacturing industries, based on the CIS1 micro-aggregated firm data.

The paper is organized as follows. In section 2, we develop the idea of an accounting framework for innovation. In section 3, we lay out the econometric model which underlies such framework and is consistent with the nature of the innovation survey data. In section 4, we describe the CIS1 micro-aggregated data we use. In section 5, we present and interpret the estimation results. In section 6, on the basis of these results and along the lines of our framework, we proceed with the comparison of the innovation performance of the seven European countries. We summarize the main points of the analysis in the concluding section.

\section{ACCOUNTING FOR INNOVATION AND ACCOUNTING FOR PRODUCTIVITY: A PARALLEL}

The innovation surveys provide us with a very interesting new way of measuring the output of firms' innovative activities, namely the share of sales in the last year (i.e. 1992 for CIS1) due to new and substantially changed products introduced on the market during the last three years (i.e., 1990-1992 for CIS1), or the share of innovative sales for short. This measure can be viewed simply as a sales weighted number of innovations and seems to be generally well understood by firm respondents. It also offers various possible refinements such as distinguishing between incremental or radical improvements, or between products new to the firm or new to the market. Of course such a measure only captures product innovations, but the surveys indicate that most firms innovating in 
processes also innovate in products. ${ }^{4}$ Process innovations do not directly show up in new sales, if their only effect is to reduce the cost of producing old products. However, they also lead in general to new or improved products through a change in product design or quality.

Merely comparing statistics on the share of innovative sales or other innovation indicators is useful but does not say why these indicators differ across firms, sectors or countries. To understand why they do and possibly build more informative innovation indicators, we need a model. If an exact model of innovation in its various dimensions existed and we knew it, we should be able to understand precisely why, for example, one country has a higher innovation performance than another country. Of course, such a perfect model does not exist and we shall never be able to characterize and explain the innovation process fully. Nevertheless, it is worth trying to model differences in innovative performance. Even a rather crude model may allow us to assess, at least approximately and tentatively, to what extent some important innovation factors, like firm size or R\&D efforts, account for differences in innovation output. In such an endeavor, what remains to be explained is as important to measure as what can be explained. On the one hand what we call innovativity reflects the ability to turn the innovation factors accounted for in the model into innovation output, on the other hand it corresponds to other factors not measured, let alone unveiled, that challenge the researcher on innovation to probe further.

\footnotetext{
${ }^{4}$ In CIS1 the proportion of firms that declared to be only process innovators (and not product innovators) seemed particularly small; it is also relatively small in CIS2 and CIS3.
} 
To be more explicit and better motivate our approach, it is helpful to draw a comparison with the standard framework for output growth or productivity accounting. Output is viewed as being produced by inputs in a process that can be represented and analyzed by a production function. The production function in turn underlies an accounting framework, in which the difference in output between two periods (years, decades) or between two spatial units (firms, industries, countries) can be ascribed to differences in the inputs, and to a residual difference in what is called total or multifactor productivity (TFP or MFP), or simply productivity. Likewise, innovation output can be viewed as resulting from a process of transformation which can be summarized by an innovation function, even if this process is much less predictable than a production process. This innovation model can also give rise to an accounting framework in which differences in innovation output between two periods, or two spatial units, can similarly be ascribed to differences in direct inputs of innovation, and more generally contextual or environmental determinants, and to a residual difference in what can be called innovative productivity or innovativity.

This parallel between productivity and innovativity is fairly straightforward when both are measured on the basis of an econometrically estimated relationship. The analogy is less clear when productivity analysis is based on "accounting data" and index number computations. In this approach total or multifactor productivity is not estimated as a residual but computed as the ratio of an output index to a weighted index of inputs, where the weights are taken to be equal to the corresponding input shares (in total revenue or total cost) available from firms' current accounts or country national accounts. In practice, it is impossible to measure innovativity by such index number method in the absence of 
similar accounting information for innovation outputs and inputs. In theory, that might not be unconceivable if well developed and functioning markets for innovation outputs and inputs existed in the economy, where one could assume that in the long run relative prices and marginal productivities would tend to be equal. In such an hypothetical world, firms' current accounts (and balance sheets) could describe and measure innovation activities, as they do for production activities, and thus provide the necessary information for the computation of an index measure of innovativity, as for that of productivity.

The analogy between the two types of analyses could be pursued further to highlight basic similarities, as well as essential differences. For example, the methodological problems raised by extending a bilateral productivity comparison to a multilateral one carry over to comparisons of innovation. In the case of a bilateral comparison it is straightforward to compare the observations in one country with those in the other country. In a multilateral comparison, it is useful to refer to a non-arbitrary fixed point of comparison. If various firms of a given industry are compared, the reference point would be the average firm; if various industries of a given country are compared, it would be the average industry, and so on. As we are comparing here the innovation performance in seven European countries, our choice for base of comparison will simply be the hypothetical "average Europe", where each of these countries is given equal weight. ${ }^{5}$

5 Our application of the innovation accounting framework bears a close resemblance to the interspatial multilateral productivity comparisons introduced by Caves, Christensen and Diewert (1982). They recommend the use of a transitive multilateral productivity index (based on an approximation to a general production function), treating all countries symmetrically by comparing them to a hypothetical country, 
In both types of analysis, the major challenge is to account for as many explanatory factors as possible within the limits of available information. In our case, we are strictly limited to the CIS1 micro-aggregated dataset. In addition to the usual R\&D intensity variable, we are able to consider a few other explanatory variables measuring or proxying for firm organizational characteristics or external conditions propitious to innovation activities. The econometric specification of the innovation model and its estimation are thus largely conditioned by the availability and nature of the data. We now turn to a presentation of the innovation model as we could specify it and estimate it on the basis of the CIS1 data.

\section{THE INNOVATION MODEL: ECONOMETRIC SPECIFICATION AND ESTIMATION}

The CIS questionnaires, like other innovation surveys, are set up in a way that gives rise to censoring or selection problems. First, firms are asked some general questions such as their total sales, their number of employees, their industry affiliation, and whether they belong to a group of firms. Then, they have to answer a few central filtering questions to determine whether or not they are "innovating" firms. Innovating firms are those answering that in the last three years (i.e., 1990-1992 for CIS1) they have developed new or changed products, or new or changed processes, or that they intend to do so in the near

which takes arithmetic average values for all variables entering the productivity formula (or geometric averages if these variables are expressed in logarithms). 
future. ${ }^{6}$ Only innovating firms have to fill out the full questionnaire, while noninnovating firms are only asked about their perception of the degree of importance of various obstacles hampering innovation. CIS surveys thus basically provide rich information for firms which are innovating but little for firms which are not. If we limited ourselves to use the information available for all firms, we could at best account for their "propensity to innovate", but we would fail to exploit most of the information we have on innovating firms, in particular regarding their innovation output and more precisely their innovative sales. Therefore, we chose to specify an econometric model which exploits the data of all firms, innovating or not, and which also accounts for firms' innovation output or "intensity of innovation". The estimated model can then be used to compute expected innovation intensity, controlling for a set of "exogenous" variables, and our indicator of innovativity, defined as the residual difference between observed and expected innovation intensity. $^{7}$

More precisely, we adopt a generalized (Type 2) Tobit model consisting of two equations, where the first one is a probit equation determining whether a firm innovates

\footnotetext{
${ }^{6}$ This is the actual definition of innovating firms in CIS1. In CIS2 and CIS3 firms declaring that during the last three years they have not yet completed or that they have abandoned innovation activities are also considered as "innovating" firms.

${ }^{7}$ Porter and Stern (1999) do a similar type of analysis, as we do here, although they do not cast it in terms of an accounting framework for innovation. They define an expected innovation intensity index in terms of expected international patents per head conditional on resource, environment and demand conditions. They compute their index by estimating a regression on a panel of 17 OECD countries over a 21-year period. While their measure is based directly on aggregated country data, ours is based on micro-data, and we therefore need to model the propensity to innovate as well as the intensity of innovation.
} 
or not, and the second one is a linear regression (or Tobit equation) explaining how much the firm innovates (see for example Maddala, 1983; Amemiya, 1985; Greene, 2003; or Wooldridge, 2002). We assume that there is a latent variable $y_{1 i}^{*}$ for firm $i$ that is generated by the first equation

$$
y_{1 i}^{*}=x_{1 i} b_{1}+u_{1 i}
$$

where $x_{1 i}$ is a vector of explanatory variables, $b_{1}$ is a vector of parameters to be estimated, and $u_{1 i}$ is a random error term, which includes the effect of left-out variables omitted due to the lack of appropriate data and our limited knowledge of the innovative process. This equation is interpreted as saying that if $y_{1 i}^{*}$ is positive, incentives to innovate are large enough for the firm to actually innovate. Denoting by $y_{1 i}$ the binary variable indicating that firm $\mathrm{i}$ is an innovating firm, we can thus write:

$$
y_{1 i}=\left\{\begin{array}{l}
=1 \cdots \cdots \cdot \text { if } \cdots y_{1 i}^{*}>0 \\
=0 \cdots \cdots \cdot \text { if } \cdots y_{1 i}^{*} \leq 0
\end{array}\right.
$$

As explanatory variables $x_{1 i}$ we can use industry dummies, firm size and group membership. Industry dummies capture technological opportunity conditions (i.e. it is easier to innovate in certain fields than in others), industry-targeted innovation policies, an industry-specific differential demand growth effect (for instance, demand is growing for electronic products but declining for textile products), or structural effects like the intensity of competition. Size, measured by the number of employees, reflects access to finance, scale economies, and differences in the organization of work. Firms that are part of a group (i.e. controlled by another firm) are expected to benefit from intra-group 
knowledge spillovers, internal access to finance, or various other synergies (in marketing, distribution, etc), and therefore to be more innovative.

Three other variables are in principle available in CIS1 micro-aggregated data for all firms irrespective of whether or not they are innovators. Past growth can be a determining factor of innovation, as reflecting both a stronger demand and an easier access to internal and external finance (see Brouwer and Kleinknecht, 1999). Unfortunately, the growth rate in firm sales (in the three year period 1990-92) is missing for Norway and Germany, and hence we could not actually use it to control for past growth in a common model for all the seven countries considered. We could also have considered the proportion of exports in total sales as an indicator of external competition stimulating innovation. However, it would be a very unsatisfactory indicator, since it is not likely to be exogenous. Exports can be driven by innovation, as new products open up new markets abroad, and both innovative sales and export intensity can also result from past innovative efforts. A third variable available with observations for both innovating and non-innovating firms is the degree of importance of the obstacles to innovation. Although this should be a priori a very important factor in explaining why firms will not innovate, various authors have found that the obstacles to innovation are more strongly perceived when firms actually innovate and face those obstacles than when they do not innovate and hence do not encounter them (Baldwin and Lin, 2001, Mohnen and Rosa, 2002). Hence, this variable cannot be taken as exogenous to being innovative (actually it can be negatively correlated with being innovative), and we prefer not to include it in the model. 
In the CIS surveys firms' innovation intensity can be measured by the share of innovative sales in total sales and thus their innovation output level by the magnitude of innovative sales (measured as the share of innovative sales multiplied by total sales). It is also possible to distinguish between innovative sales corresponding to products new to the firm but possibly known to the market, which can be considered as imitations of products already produced by other firms in the industry, and those corresponding to products only new to the market, which can be regarded as true innovations (see, for example, Brouwer and Kleinknecht, 1996). In the analysis here we preferred to simply focus on the overall measure. ${ }^{8}$ The second equation of our generalized Tobit model is thus specified in terms of a second latent variable $y_{2 i}^{*}$, which is equal to the actual share of innovative sales $y_{2 i}$, if the firm is innovative (i.e. $y_{1 i}^{*}>0$ ). Since the share of innovative sales is bounded by 0 and 1 (i.e., $0<y_{2 i} \leq 1$ ), it is actually preferable to specify this second equation in terms of the latent logit-share variable $z_{2 i}^{*}=\ln \left(y_{2 i}^{*} /\left(1-y_{2 i}^{*}\right)\right)$ which can vary from $-\infty$ to $+\infty$. Because the resulting variable is closer to normally distributed, the maximum likelihood estimator is then more likely to be consistent for the underlying parameters. We have $y_{2 i}^{*}=e^{z_{2 i}^{*}} /\left(1+e^{z_{2 i}^{*}}\right)$. Similarly $\quad$ if $\quad z_{2 i}=\ln \left(y_{2 i} /\left(1-y_{2 i}\right)\right) \quad$ is the observed logit share variable, then $y_{2 i}=e^{z_{2 i}} /\left(1+e^{z_{2 i}}\right) \cdot 9$

\footnotetext{
${ }^{8}$ The information on shares of innovative sales for products new to the market is not available for all seven countries. There is also a breakdown of sales with respect to various stages of the product life-cycle, but we have not tried to exploit this information.

${ }^{9}$ Note that the logit share variable $z_{2 i}$ is not defined for the two bounds 0 and 1 of the share of innovative sales $y_{2 i}$. In practice, we deal with the upper bound of 1 by simply setting the value of $y_{2 i}$ to 0.99
} 
The second equation of the generalized Tobit model is thus the following:

$$
z_{2 i}^{*}=x_{2 i} b_{2}+u_{2 i}
$$

where $x_{2 i}>0$ is a vector of explanatory variables, $b_{2}$ is a vector of parameters to be estimated and $u_{2 i}>0$ is a stochastic error term reflecting omitted variables and other sources of heterogeneity. Note that because of the logit share transformation of equation (2), $u_{2 i}$ varies from $-\infty$ to $+\infty$. We can therefore write:

$$
z_{2 i}=\left\{\begin{array}{l}
=z_{2 i}^{*} \cdots \cdots \cdots \cdots \cdot \text { if } \cdots y_{1 i}^{*}>0 \\
=\text { undefined } \cdots \text { if } \cdots y_{1 i}^{*} \leq 0
\end{array}\right.
$$

or equivalently:

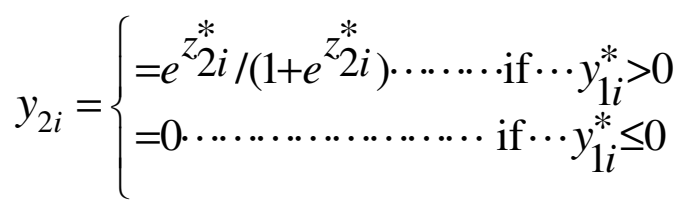

Although it would be helpful for identification, we cannot exclude any of the explanatory variables we have in $x_{1 i}$ from $x_{2 i}$ a priori. However, since for innovating firms we have information on more variables, we can include in $x_{2 i}$ six other variables which are relevant for explaining innovation intensity: four relating to $\mathrm{R} \& \mathrm{D}$ (assumed to be the main innovation input) and two binary indicators characterizing the environment in which the firm operates - one for the strength of competition and the other for proximity to basic research. Competition is deemed to be strong (the indicator is 1) when firms

whenever it is higher (and less or equal to 1). By symmetry, we also set the $y_{2 i}$ to be 0.01 whenever it is smaller and positive. See for example Cragg (1971) for a rigorous treatment of a Tobit model with both a lower and an upper bounded dependent variable. 
declare that increasing or maintaining market share is an important objective of innovation for them, and weak if it is not (the indicator is 0 ). Similarly, proximity to basic research is significant when firms answer that universities/higher education or government laboratories are significant sources of information for innovation. ${ }^{10}$ The four R\&D-related variables are a binary indicator for R\&D-performing firms, the R\&D/sales ratio for $\mathrm{R} \& \mathrm{D}$ performing firms, a binary indicator for doing $\mathrm{R} \& \mathrm{D}$ on a continuous basis, and one indicating whether R\&D is done in cooperation with partners or not. ${ }^{11}$

Following the standard procedure we estimate our generalized Tobit model by maximum likelihood, assuming that $u_{1 i}$ and $u_{2 i}$ are independently and identically jointly distributed as a bivariate normal distribution with mean zero and contemporaneous variance-covariance matrix $\Sigma=\left[\begin{array}{cc}\sigma_{1}^{2} & \sigma_{12} \\ \sigma_{12} & \sigma_{2}^{2}\end{array}\right]$. Because $\sigma_{1}$ cannot be identified, it is

${ }^{10}$ Firms have to provide answers on their innovation objectives and sources of information using a fivepoint Likert scale, and the cut-off values we chose to define our dichotomous indicators correspond roughly to the sample median responses.

${ }^{11}$ Another potentially interesting innovation input variable contained in CIS 1 corresponds to the notion of innovation expenditures, including $R \& D$ but also the expenditures on acquisition of patents and licenses, product design, trial production, training and tooling-up, and market analysis. Unfortunately either this variable was misunderstood by the respondents or firms were not used to keeping account of those expenditures. In many cases, for example, this variable took values lower than the $R \& D$ expenditures, declared elsewhere, that it is supposed to include. For these reasons we excluded this variable from the analysis. We have also decided not to include in the explanatory variables the perceived strength of appropriability of product or process innovations, because of the particular difficulty of assuming that it enters exogenously in the model (likewise the perceived obstacles to innovation variable). 
normalized to be equal to 1 , and $\sigma_{12}=\rho \sigma_{2}$ where $\rho$ is the contemporaneous correlation coefficient between the two error terms. The log-likelihood function of our sample is the following:

$$
\begin{aligned}
\ln L= & \sum_{0} \ln \left[1-\Phi\left(x_{1 i} b_{1}\right)\right]+\sum_{1} \ln \Phi\left(\frac{x_{1 i} b_{1}+\rho / \sigma_{2}\left(z_{2 i}-x_{2 i} b_{2}\right)}{\sqrt{1-\rho^{2}}}\right) \\
& +\sum_{1} \ln \left\{\left(1 / \sigma_{2}\right) \varphi\left[\left(\ln \left(z_{2 i}\right)-x_{2 i} b_{2}\right) / \sigma_{2}\right]\right\}
\end{aligned}
$$

with the index 0 and the index 1 under the summation signs referring respectively to noninnovating and innovating firms (i.e., $y_{1 i}=0$ and $y_{2 i}=1$ ), and $\Phi$ and $\varphi$ being respectively the standard normal univariate distribution and density functions. ${ }^{12}$

We estimate the model on the pooled data of the seven countries, accounting for country-specific and industry-specific effects by way of country and industry dummy variables. We thus assume a common structure that applies to all countries and that can later be used to compare innovation performance across countries. We also put all seven countries on an equal footing, irrespective of the size of their respective samples, by weighting appropriately the variables pertaining to each country (that is by the square root of $\mathrm{N}_{\mathrm{E}} / \mathrm{N}_{C}$ where $\mathrm{N}_{C}$ is the number of firms in country $\mathrm{C}$ and $\mathrm{N}_{\mathrm{E}}$ is the average number of

\footnotetext{
${ }^{12}$ The first term of the likelihood function (3) defined over the non-innovating firms is the same as the corresponding term in the likelihood function for the probit equation, while, when $\rho=0$, the second term defined over the innovating firm becomes also the same as the corresponding term in the likelihood function for the probit equation. The third term is the likelihood function for the linear regression over the innovating firms. To ensure that the estimated $\sigma_{2}$ is positive, it is replaced by $\exp (\omega)$ in the likelihood function, and to ensure that the estimated $\rho$ stays between -1 and 1 , it is replaced by $(\exp (2 v)-1) /(\exp (2 v)+1)$. Initial estimates are obtained from Heckman's two-step estimation (see Heckman, 1979).
} 
firms per country, say in our hypothetical "average Europe"). ${ }^{13}$ Imposing a common model structure and giving equal weight to the seven countries means that the estimated coefficients $b_{1}$ and $b_{2}$ in the innovation propensity and intensity equations (and the corresponding marginal effects) are to be viewed as "average Europe" coefficients. It means also that our indicator of innovativity is to be interpreted as measuring not only the effects of the unobserved factors of innovation, but possibly also differences across countries in the model structure and estimated coefficients. ${ }^{14}$

However, in estimating our generalized Tobit model, we found that the loglikelihood function always increased with the value of the correlation coefficient $\rho$ between the error terms in both equations, raising convergence problems in maximizing the likelihood function. Various experiments with somewhat different specifications of the model led to the same conclusion. A value of $\rho$ close to one suggests that the error

\footnotetext{
${ }^{13} \mathrm{We}$ chose to give equal weight to each country. Another option, however, would have been to take as reference a representative "average Europe", by using grossing-up factors to "blow up" the country samples to the entire country populations. Note that this option raises a number of practical problems. Even if one would use the weighting factors for each stratum of firms (defined by size and industry) provided by Eurostat, it would imply that non-responding units behave in the same way as the responding units. As a rule of thumb, such an assumption seems unlikely when the percentage of non-responses exceeds $25 \%$ (see Archibugi et al., 1994), and none of our seven countries satisfies this condition.

${ }^{14}$ Estimating different models for each country would make it possible in principle to take apart these two components, by allowing us to account separately for differences in expected innovation intensity arising from differences in the model structure across countries and those arising from the differences in average magnitudes of explanatory variables across countries (for a common model structure). In the present
} 
terms in both equations are nearly collinear and that common unobserved factors of innovation are omitted in both parts of the model. ${ }^{15}$ We therefore ended up fixing the value of $\rho$ to 0.95 , the estimated coefficients of the model not being too sensitive to the exact value of $\rho$ around $0.90-0.99$. It is clear, however, that we have an identification problem, most likely due to the poor specification of the first equation (the probit equation) as a result of the lack of variables that could predict when firms are innovators. ${ }^{16}$ We intend to investigate further this issue in future work in which the CIS surveys could be matched to complementary sources of data. Nonetheless we think that, at least for our mainly illustrative purpose here, the compromise we finally adopted is satisfactory.

\section{COUNTRY SAMPLES AND SIMPLE DESCRIPTIVE STATISTICS}

illustrative analysis, we did not pursue this possibility, many of the parameters of our model being poorly estimated at the country level (and hence not significantly different across countries).

${ }^{15}$ We were of course expecting a priori a high positive value of $\rho$, if only because of the omission of unobserved factors of innovation in the probit and Tobit equations, such as the quality of management and the environment of the firm. Estimating a simple Tobit model, which in a sense corresponds to a limiting case of $\rho=1$ is unsatisfactory. In particular we would be restricted to two explanatory variables, those entering equation (1) of the generalized Tobit model (apart from the industry and country dummies).

16 As our model stands, the identification of the probit and Tobit equations is based on the functional assumption of joint normality of $u_{1 i}$ and $u_{2 i}$. We would have preferred to base identification on exclusion restrictions, that is, on the exclusion in the Tobit equation (in $x_{2 i}$ ) of variables belonging to the probit equation (in $x_{1 i}$ ). See for example Puhani, 2000. 
As usual when working with firm level data, in order to construct country samples that we could use in our analysis, we had first to clean the CIS1 micro-aggregated raw data for outliers, missing observations, and inconsistencies. We thus eliminated all firms with less than 20 employees, because these firms were not surveyed in four of our seven countries. We also deleted firms with missing industry affiliation and restricted our samples to manufacturing industries, since only two countries (Germany and the Netherlands) had collected data on services. We also purged from our samples all firms with sales growth rates between 1990 and 1992 higher than $250 \%$ and lower than $-40 \%, \mathrm{R} \& \mathrm{D} / \mathrm{sales}$ ratios higher than 50\%, current expenditures on innovations higher than $100 \%$ of their sales. We set $\mathrm{R} \& \mathrm{D} / \mathrm{sales}$ ratios to zero when they were positive but lower than $0.1 \%$. As the Italian sample resulted from a census and not a survey, the Italian sample was ten times greater than the second largest country sample, Germany. We therefore took (after cleaning) a random subsample for Italy consistent with the sampling frame adopted by the other countries, by keeping 5\% of all firms with 20 to 49 employees, $10 \%$ of all firms between 50 and 249 employees, and all firms with more than 250 employees. In the end we were left with 8146 observations overall: 542 in Belgium, 572 in Denmark, 1910 in Germany, 715 in Ireland, 2254 in Italy, 1678 in the Netherlands, and 475 in Norway.

We distinguished eleven industries in total manufacturing, whose definition, abbreviated names and related NACE codes are listed in Table B1 in Appendix B. In defining these industries we made sure that we had enough observations per industry in each country, starting from the industry aggregate classification used by Eurostat (1997) in presenting the descriptive statistics of the CIS 1 survey, and aggregating it further when needed. In our analysis, we considered separately the high-R\&D industries (Vehicles, 
Chemicals, Machinery and Electrical) and the low-R\&D industries, or high-tech and lowtech industries, based on previous econometric evidence of important differences between them (see for example Griliches and Mairesse, 1984). The numbers of firms per industry in the seven countries are given in Table B2 in Appendix B.

We have defined innovating firms in a somewhat more restrictive way than in the CIS1 surveys, where they are all the firms that answer yes to any of the questions "Have you introduced a new or technologically changed product during 1990-1992?", "Have you introduced a new or technologically changed process during 1990-1992?", "Do you intend to innovate in the next three years?". Nearly $10 \%$ of the firms, however, declaring that they have introduced new or changed products do not answer the questions on the shares of innovative sales for incrementally changed, significantly changed or newly introduced products, or they report zero shares. One explanation is that they do not know the answer to the question or that there can be a significant time lag between the introduction of a new product on the market and the realization of non negligible sales from this new product. As we have only cross-sectional data, we have decided to be more restrictive in the definition of an innovating firm by characterizing it as one that declares a non-zero share of innovative sales for incrementally changed, significantly changed or newly introduced products in the three years $1990-1992 .{ }^{17}$ Finally, about $4 \%$ of the firms

\footnotetext{
${ }^{17}$ Alternatively, we could have treated as zero responses all the non-responses on the share in sales of innovative products by firms that declare to be innovators, and we could have replaced all these zero shares by a 0.01 share because of our logit-share transformation. Some experiments led us to conclude that this alternative treatment would have little bearing on the results. Note that the distinction between nonresponses and zero responses is not reliable both because it is unlikely that firms themselves always make
} 
report that their sales are entirely due to new or improved products. Since the logit-share transformation is not defined in this case, we have simply assumed that the share of innovative sales is at most 0.99 , and, by symmetry, for the handful of firms for which the share of innovative sales was positive but less than 0.01 , we set it to be at least equal to 0.01 (see footnote 9).

Table 1 gives the means of all the variables used in our analysis for our seven country samples, separately for the high-tech and low-tech sectors. Table 1 gives also these means for our hypothetical average Europe, which serves as our reference country, where these means are simply computed as the arithmetic average of the corresponding seven country means (thus giving equal weight to each country). About $35-40 \%$ of the firms in the country samples belong to the high-tech sectors, with the exception of Germany where this proportion is as high as 55\%. Overall, firms in the high-tech sectors differ from those in the low-tech sectors in many respects. They are larger and therefore account for a relatively greater fraction of total employment. They are more often part of a group; they have a higher percentage of innovators (73.8\% as opposed to $55.8 \%)$; they feel more pressure from competition $(69.7 \%$ as opposed to $53.1 \%)$ and are more closely connected with basic research $(58.1 \%$ as opposed to $41.1 \%)$. Firms in high-tech sectors, when they innovate, have on average a higher share of innovative sales $(46.8 \%$ against $38.9 \%)$; they perform R\&D more frequently (90.2\% against $77.7 \%$ ) and more intensively (with an $\mathrm{R} \& \mathrm{D}$ to sales ratio of $4.4 \%$ against $2.0 \%$ ). When they do $\mathrm{R} \& \mathrm{D}$, they do it more often in a continuous fashion (81.9\% against $72.2 \%)$ and in cooperation with others 
(81.9\% against $42.5 \%)$. The simple dichotomy between "high-tech" and "low-tech" firms in the analysis thus controls for quite a number of systematic differences.

Across the country samples, there are also a number of important differences. The size distribution is more skewed towards large firms in Belgium and Germany than in the other countries, especially in the high-tech sectors. Ireland on average has the smallest firms. Germany has the highest proportion of innovating firms and the highest share of innovative sales in both the high- and low-tech sectors. The lowest percentages of innovating firms are in Italy and Norway. Norwegian innovating firms, however, have almost the same share of innovative sales (48.2\%) in the high tech sectors as the country leader Germany. Doing R\&D continuously is most common in Belgium and Italy and least frequent in Denmark, whereas cooperative R\&D is often encountered in Denmark and Norway, but only rarely in Italy. Pressure of competition and proximity to basic research are strong in Belgium and Germany and weak in Italy and Norway.

\section{ESTIMATION RESULTS: COEFFICIENTS AND MARGINAL EFFECTS}

Our estimation results are presented in details in Tables 2 and 3. Table 2 shows the pooled estimates of the coefficients of the generalized Tobit model, estimated separately for firms in the high-tech and low-tech sectors, and controlling for unexplained industry and country heterogeneity by introducing industry and country dummies in each of the two equations of the model. Size is measured by the logarithm of the number of employees in deviation from the size of the average European firm and the R\&D/sales ratio is also defined in deviation from the corresponding ratio of the average European country. The reference group is the food industry for the low-tech sectors or the motor 
vehicles industry for the high-tech sectors, in Denmark, with no R\&D, not belonging to a group, experiencing little competition and not benefiting much from basic research. ${ }^{18}$

Most estimated coefficients are significantly different from zero, although there are not too precisely estimated. Many of them are also markedly different from each other in the high- and low-tech sectors, even if not statistically so (at the conventional level of significance of 5\%). We find an estimated coefficient of R\&D in the low-tech sectors that is twice as high as that in the high-tech sectors, although R\&D-doing firms in these sectors innovate much less in average than those in high-tech sectors. Low-tech firms also appear to benefit less from size, from being close to basic research, from the pressure of competition, and from cooperation in $\mathrm{R} \& \mathrm{D}$. In contrast, they are more likely to innovate if they are part of a group.

For a better assessment of the estimated coefficients, we proceed in Table 3 to an analysis of the marginal effects of each variable (the equivalent of the slope in a linear regression). We distinguish three types of marginal effects, those on the expected propensity to innovate, those on the expected intensity of innovation unconditional on being innovative and those on the expected intensity of innovation conditional on being innovative. These expected functions are respectively given by:

\footnotetext{
${ }^{18}$ In Germany we have many instances of missing values for the variable "belonging to a group". Small firms had a separate questionnaire to fill out in which this question was not listed. Instead of considering these firms as not belonging to a group, we have introduced a separate dummy variable to control for these missing values. We have also introduced other dummy variables to control for missing $R \& D / s a l e s$ ratios for a number of R\&D doing firms in the quantitative part of the model, instead of considering these firms as non-R\&D performers or dropping them from our samples. The coefficients of these missing values control dummies are not reported in Table 2.
} 


$$
\begin{aligned}
& E\left(y_{1 i} \mid x_{1 i}, x_{2 i}\right)=E\left(y_{1 i} \mid x_{1 i}\right)=\Phi\left(x_{1 i} b_{1}\right) \\
& E\left(y_{2 i} \mid x_{1 i}, x_{2 i}\right)=\int_{-\infty}^{\infty} \int_{-\infty}^{\infty} y_{2 i} f\left(u_{1 i}, u_{2 i}\right) d u_{1 i} d u_{2 i}=\int_{-x_{1 i} b_{1}}^{\infty} \int_{-\infty}^{\infty} y_{2 i} f\left(u_{1 i}, u_{2 i}\right) d u_{1 i} d u_{2 i} \\
& E\left(y_{2 i} \mid x_{1 i}, x_{2 i}, y_{1 i}=1\right)=\int_{-x_{1 i} b_{1}}^{\infty} \int_{-\infty}^{\infty} y_{2 i} f\left(u_{1 i}, u_{2 i} \mid u_{1 i}>-x_{1 i} b_{1}\right) d u_{1 i} d u_{2 i} \\
& \text { or } \\
& E\left(y_{2 i} \mid x_{1 i}, x_{2 i}, y_{1 i}=1\right)=\left[E\left(y_{2 i} \mid x_{1 i}, x_{2 i}\right)\right] / \Phi\left(x_{1 i} b_{1}\right)
\end{aligned}
$$

We evaluate all three expected functions at the estimated values of the model coefficients $\left(b_{1}, b_{2}, \rho\right.$ and $\left.\sigma_{2}\right){ }^{19}$ We compute the corresponding marginal effects at the mean values of the explanatory variables, respectively for all the firms in the case of $E\left(y_{1 i} \mid x_{1 i}\right)$ and $E\left(y_{2 i} \mid x_{1 i}, x_{2 i}\right)$ and the innovating firms only in the case of $E\left(y_{2 i} \mid x_{1 i}, x_{2 i}, y_{1 i} \geq 0\right) .{ }^{20}$ For the continuous variables, size and R\&D intensity, we take the derivatives of the expected functions with respect to those two variables. For the binary indicators, other than industry and country dummies, we calculate the marginal effects as the differences in the values of the expected functions when the indicator goes

${ }^{19}$ We have directly computed the unconditional expected intensity of innovation by the following formula

$$
E\left[y_{2 i} \mid x_{1 i}, x_{2 i}\right]=\int_{-x_{1 i} b_{1}}^{\infty} \int_{-\infty}^{\infty} \exp \left(x_{2 i} b_{2}+\sigma_{2} u_{2 i}^{*}\right) /\left(1+\exp \left(x_{2 i} b_{2}+\sigma_{2} u_{2 i}^{*}\right)\right) f\left(u_{1 i}^{*}, u_{2 i}^{*}\right) d u_{1 i}^{*} d u_{2 i}^{*}
$$

where $u_{2 i}^{*}=u_{2 i} / \sigma_{2}, u_{1 i}^{*}=u_{1 i}$ and $f\left(u_{1 i}^{*}, u_{2 i}^{*}\right)$ is the bivariate standard normal distribution with correlation coefficient $\rho$. We compute these integrals using a Gauss-Legendre quadrature with Gauss software. Note that if we had not preferred to make the logit-share transformation, we could have more simply written $E\left[y_{2 i} \mid x_{1 i}, x_{2 i}\right]=\int_{-x_{1 i} b_{1}}^{\infty} \int_{-\infty}^{\infty}\left(x_{2 i} b_{2}+u_{2 i}\right) f\left(u_{1 i}, u_{2 i}\right) d u_{1 i} d u_{2 i}$, which can easily be expressed as $E\left[y_{2 i} \mid x_{1 i}, x_{2 i}\right]=\Phi\left(x_{1 i} b_{1}\right)\left(x_{2 i} b_{2}\right)+\rho \sigma_{2} \varphi\left(x_{1 i} b_{1}\right)$, that is Heckman's formula (see Greene, 2003).

\footnotetext{
${ }^{20}$ Note that, if the expected functions were linear, the marginal effects would be constant (and that they would not depend on the values the variables).
} 
from 0 to 1 . We express the marginal country effects as the differences between the values of the expected functions when having the country-specific dummy and the average of the country dummy coefficients for the seven countries, and we similarly define the marginal industry effects as the differences between having the industryspecific dummy coefficient and the average of the industry dummy coefficients weighted by the average industry composition in the seven countries. The country and industry effects are thus interpreted as deviations from the average country and average industry effects (see Suits, 1984). ${ }^{21}$

The two first columns of Table 3 show that a $1 \%$ increase in size for the average European firm in the high-tech sectors (corresponding roughly to 6 additional employees) and in the low-tech sectors (corresponding roughly to only 3 additional employees) would increase the probability of innovating by about $10 \%$. They also show that a firm belonging to a group has on average a higher probability of innovating than one which does not, by about $5 \%$ in the high-tech sectors and $10 \%$ in the low-tech sectors. It appears that German firms are more often innovative than the average European firm (by about $10 \%$ in the high-tech sectors and 15\% in the low-tech sectors). So are the Irish and Dutch firms, and the Belgian firms in the low-tech sectors. By contrast, for reasons to be investigated (other than average industry composition, the average size or being part a group), far fewer firms are innovative in Italy (by about 15\% in the high-tech sectors and $35 \%$ in the low-tech sectors). The frequency of innovation is higher in the industries

\footnotetext{
${ }^{21}$ Note that if the expected functions were linear, the sum of the country effects and that of the industry effects weighted by the average industry compositions would both be equal to zero (and that any deviation from zero in the sum of these effects is thus due to the nonlinearity).
} 
producing machinery and equipment and electrical and electronic products than in those producing vehicles and chemicals. Among the low-tech sectors, the proportion of innovators is particularly low in the wood-based and textile-producing industries.

Turning to the marginal effects of the explanatory variables on the expected intensity of innovation for firms that already innovate (given in the third and fourth columns of Table 3), we see that we see that returns to scale are practically constant for the average European innovating firm in the high-tech sectors and slightly decreasing in the low-tech sectors in the low-tech sectors. Being part of a group has also a very small impact. Doing R\&D also entails a rise of the share of innovative sales of about $4 \%$ in the high sectors and $1.5 \%$ in the low-tech sectors; and doing it continuously an additional rise of about $4.5 \%$ in both sectors. A one percentage point raise of the $\mathrm{R} \& \mathrm{D} / \mathrm{sales}$ ratio for R\&D doing firms corresponds respectively to an increase of the share of innovative sales of $0.25 \%$ in the high-tech sectors and one of $0.55 \%$, more than the double, in the low tech-sectors. ${ }^{22}$ The effects of competition and proximity to basic research are quite sizeable in the high-tech sectors, much less in the low-tech sectors.

If we do not limit ourselves to the innovating firms, the marginal effects encompass the combined effects on the propensity to innovate and on the intensity of innovation when firms innovate. These marginal effects (given in the fifth and sixth columns of Table 3) tend to be smaller than the corresponding conditional effects. However, the joint effects of size and group, those of doing R\&D and doing it continuously and in cooperation, and those of proximity to basic research and perceived

\footnotetext{
${ }^{22}$ These estimated marginal impacts of R\&D intensity on innovation intensity (conditional on both doing $R \& D$ and being innovative) seem particularly small, which may be due to various specification problems to be investigated in future work..
} 
competition remain very substantial in the high-tech sectors, and to a large extent in the low-tech sectors as well. It is interesting to observe that the marginal effect of the R\&D to sales ratio variable (computed at the average European ratio in both sectors) remains about $50 \%$ higher in the low-tech sectors than in the high-tech sectors.

\section{ACCOUNTING FOR INNOVATION: AN ILLUSTRATION}

We can now move to the illustration of our accounting for innovation framework and the measurement of innovativity. In Table 4, we provide, separately for the high-tech and low-tech sectors, a decomposition of the innovation performances for each of the seven countries in terms of "structural effects" (the effects of the main explanatory factors of innovation that we have been able to consider) and of innovativity, respectively for the propensity to innovate (panel A), the innovation intensity for the innovating firms (panel B), and innovation intensity unconditional on being innovative (panel C). As it is set up, Table 4 allows for a comprehensive comparison of the innovation performance of any given country relative to the average European country, and hence for any bilateral or multilateral comparison between any two or more of the seven countries. A detailed explanation of how this table is constructed, based on our estimated model, is given in Appendix A.

The different structural effects and innovativity are all expressed in the three panels of Table 4 in terms of deviations from the average European country. We thus start in the first column, for each country, from the common average European values for the innovation propensity and the conditional and unconditional innovation intensity indicators. We show next, in the following columns, the estimated structural effects 
grouped in four categories: industry composition, size and belonging to a group, the four $R \& D$ variables $(R \& D$ intensity and the indicators for doing $R \& D$, continuous $R \& D$ and cooperative R\&D), and the two environment indicators (perceived competition and proximity to basic research). ${ }^{23}$ We then have, in the following two columns, the sum of structural effects and the expected innovation propensity and intensity indicators, which are themselves computed by adding the structural effects to the corresponding average European indicators (in the first column). ${ }^{24}$ Finally we find for each country, in the last two columns, the estimated innovativity and the observed innovation propensity and intensities, where innovativity is obtained as the difference between the observed and expected values. $^{25}$

As we have been able to illustrate it here, for many of the possible pair-wise country comparisons, our framework imputes most of the differences in innovation performance to innovativity. and attributes relatively little of these differences to the

\footnotetext{
${ }^{23}$ We have only the first two groups of structural effects for the innovation propensity in panel A. We have added the dummy variable for missing values on the variable belonging to a group to the German country effect (as it affects German firms only), and have regrouped the dummy variable for the missing values on $R \& D / s a l e s$ ratios for the $R \& D$ doing firms with the four $R \& D$ variables.

${ }^{24}$ Note that the expected marginal effects so computed are the ones we directly estimate for each country from equations (4), (5) and (6), but up to an approximation error due to the linearization of the effects around the average European country (see Appendix A).

${ }^{25}$ Note that the country effect is not treated as a structural effect, but that it constitutes the main component of innovativity, the two other components of innovativity, as we compute it here, being the two approximation errors due to the intrinsic non linearity of the expected marginal effects and to the linearization around the average European country (see Appendix A).
} 
structural effects. This is particularly true for all three innovation indicators in the lowtech sectors, but much less so in the high-tech sectors. Let us consider two extreme cases: firstly the comparison between Germany and Italy, which appear respectively as the most and the least innovative of the seven countries, both in the low- and high-tech sectors and for the three innovation indicators; and secondly the comparison of Denmark and the Netherlands, which are on the contrary very close to each other and to the average European country in terms of innovative performance.

In the high tech-sectors, the structural effects account for about one-third of the overall differences between Germany and Italy in the unconditional and conditional innovation intensities (respectively $5.5 \%$ out of $18.2 \%$, and $3.8 \%$ out of $10.2 \%$ ), but for none of the overall difference $(23.0 \%)$ in the innovation propensity. In the low-tech sectors, the structural effects account only from 5 to 10 percent of the large overall differences in the three innovation indicators (respectively $27.3 \%, 15.4 \%$ and $45.4 \%$ ). Of the 5.5\% (3.8\%) total difference in unconditional (conditional) innovation intensity, that can be attributed to the structural effects in the high-tech sectors, $3.3 \%, 1.8 \%$ and $0.9 \%$ $(2.0 \%, 0.8 \%$ and $1.2 \%)$ correspond respectively to relatively favorable differences in the environment conditions, R\&D activities and industry compositions, while only $-0.5 \%$ ($0.1 \%$ ) relates to unfavorable size and group membership effects.

In the case of Denmark and the Netherlands, we have, at least at first sight, a different picture. In the high-tech sectors, very little of the (rather small) differences between the two countries in their unconditional and conditional innovation intensity indicators is related to innovativity (about $-0.5 \%$ ), while practically all is accounted for by the structural effects (about 4\%), mainly so by the industry composition effects (about 
$2.0 \%$ ) and the R\&D effects (about 1.5\%). The situation is the same in the low-tech sectors for unconditional innovation intensity, with innovativity accounting for little ($0.3 \%)$ and the structural effects accounting fully for the small difference (1.8\%) between the two countries. It is the opposite, however, for the conditional innovation intensity, where innovativity plays a larger role $(3.6 \%)$ than the structural effects $(0.8 \%)$. The situation is also different for the innovation propensity in both sectors in the sense that innovativity and the sum of structural effects are of the same order magnitude but of opposite sign in accounting for the overall small differences ( $0.8 \%$ and $-1.8 \%)$ between the two countries.

In brief, we see that the divergence between the Germany-Italy and the DenmarkNetherlands pair-wise comparisons really concerns our estimates of innovativity, which are very large in the first comparison and small or negligible in the second, but not our estimates of the structural effects, which are more or less on the same order of magnitude in both cases. Considering other bilateral comparisons show also distinct configurations, with relative and absolute orders of magnitude of the structural effects (and their components) and of innovativity that can be quite different. ${ }^{26}$ All country comparisons are in fact case-specific, which of course is not surprising.

\footnotetext{
${ }^{26}$ For example in the high-tech industries, the case of the Denmark-Netherlands comparison appears very different from that of Ireland-Netherlands comparison, although the three countries are close to the average European country. In the first case, the small differences in the conditional and unconditional innovation intensities are mainly attributed to the structural effects, while in the latter case they are mainly imputed to innovativity.
} 


\section{CONCLUSION}

We propose in this paper an accounting for innovation framework and illustrate it by an application based on the micro-aggregated firm data from CIS1 (the first European Community Innovation Survey, covering the years 1990-1992) for the manufacturing industries in seven European countries. In this application, we measure innovation intensity by the share of innovative sales, but our framework can also be applied to other sources of data and other measures of innovation. Trying to make the best use of the qualitative and quantitative information available in the survey, we select a certain number of explanatory variables for the propensity to innovate and the intensity of innovation, and we specify and estimate an innovation function as a generalized Tobit model. Based on this model, we compute the expected share of innovative sales and define innovativity as the part of the observed share of innovative sales that remains unexplained. Innovativity corresponds to the notion of total factor productivity (TFP), or simply productivity, in production function analysis and the standard growth accounting framework. As it stands with relatively few explanatory variables our innovation framework already accounts for sizeable differences in country innovation intensity, more so in the high-tech than in the low-tech sectors. It also shows, however, that differences in country innovativity can be even more sizeable.

Given the limitations of our attempt, in particular that related to using only the micro-aggregated data from CIS1, these initial results should be merely taken as illustrative. We hope they will suffice to indicate the potential interest and advantages of explicitly implementing an accounting for innovation framework, in order to compare innovation performances between countries (as here), or between industries, or firms, 
either in terms of absolute levels in a given period (as here) or in terms of changes over time. These advantages are be similar to those of the standard growth accounting framework, in spite of the fact that in both cases many conventional decisions have to be made and many variants may be considered in setting up an appropriate framework. To make progress in future work, besides gaining experience in using innovation surveys and improving them, it will be important to be able to match the specific information they provide with the usual current accounts, balance sheets and stock market data, as well as with complementary data from other sources such as on patents and R\&D. In view of the fundamental role of research and innovation activities in our increasingly knowledgebased economies, it will also be of great interest to develop jointly productivity and innovativity analyses by combining in some systematic way an integrated production and innovation accounting framework. ${ }^{27}$

\footnotetext{
${ }^{27}$ For analyses going in this direction, see Crépon, Duguet and Mairesse (1998), and in this volume: Benavente (2006), Heshmati and Lööf (2006), Jefferson, Huamao, Xiaojing and Xiaoyun (2006), and Van Leeuven and Klomp (2006).
} 


\section{REFERENCES}

Arora, A., Ceccagnoli M. and W.P. Cohen (2003) R\&D and the Patent Premium. Cambridge, MA: NBER Working Paper 9431.

Aghion, P. and P. Howitt (1998) Endogenous Growth Theory. Cambridge, MA: MIT Press.

Amemiya, T. (1985) Advanced Econometrics, Cambridge, MA: Harvard University Press. Archibugi, D., P. Cohendet, A. Kristensen, and K.-A. Schäffer (1994) Evaluation of the Community Innovation Survey (CIS) Phase I. EIMS publication no. 11, IKE Group, Department of Business Studies, Aalborg, Denmark.

Baldwin, J. and Z. Lin (2001) Impediments to Advanced Technology Adoption for Canadian Manufacturers. Working Paper 173, Microeconomics Analysis Division, Statistics Canada.

Benavente, J.M. (2006) The Role of Research and Innovation in Promoting Productivity in Chile. Economics of Innovation and New Technology, 15(4/5). Forthcoming..

Brouwer, E. and A. Kleinknecht (1996) Determinants of Innovation: A Micro Econometric Analysis of Three Alternative Innovative Output Indicators. In A.H. Kleinknecht (ed.) Determinants of Innovation, the Message from new Indicators. London: Macmillan Press, 99-124.

Brouwer, E. and A. Kleinknecht (1999) Keynes-plus? Effective Demand and Changes in Firm-Level R\&D: an Empirical Note. Cambridge Journal of Economics, 23, 385-391.

Caves, D., L. Christensen and E. Diewert (1982) Multilateral Comparisons of Output, Input and Productivity Using Superlative Index Numbers. Economic Journal, 92, 7386. 
Cockburn, I. and Z. Griliches (1988) "Industry Effects and Appropriability Measures in the Stock Market's Valuation of R\&D and Patents". American Economic Review, Papers and Proceedings, 78(2) 419-423.

Cohen, W.M., Nelson R.R. and J.P. Walsh (2000) Protecting their Intellectual Assets: Appropriability Conditions and Why U.S. Manufacturing Firms Patent or Not. Cambridge, MA: NBER Working Paper 7552.

Cragg, J. (1971) Some Statistical Models for Limited Dependent Variables with Application to the Demand for Durable Goods. Econometrica, 39, 829-844.

Crépon, B., E. Duguet and J. Mairesse (1998) Research and Development, Innovation and Productivity: An Econometric Analysis at the Firm Level. Economics of Innovation and New Technology, 7(2), 115-158.

Eurostat (1996) Manual on Disclosure Control Methods, 9E. Luxembourg: Statistical Office of the European Communities,.

Eurostat (1997) Community Innovation Survey 1. Luxembourg: Statistical Office of the European Communities, CD-ROM.

Foray, D. (2004) The Economics of Knowledge. Cambridge, MA: The MIT Press.

Geroski, P., J. Van Reenen and C. Walters (1997) How Persistently Do Firms Innovate? Research Policy, 26, 33-48.

Greene, W. (2003) Econometric Analysis (5 ${ }^{\text {th }}$ ed.). New Jersey: Prentice Hall. Griliches, Z. and J. Mairesse (1984) Productivity and R\&D at the Firm Level. In Z. Griliches (ed.), R\&D, Patents and Productivity. Chicago, IL: University of Chicago Press, 271-297. 
Heckman, J.J. (1979) Sample Selection Bias as a Specification Error, Econometrica, 47, 153-161.

Heshmati A. and H. Lööf (2006) Knowledge Capital and Heterogeneity in Firm Performance. A Sensitivity Analysis. Economics of Innovation and New Technology, 15(4/5). Forthcoming.

Hu, X. and C. DeBresson (1998) An Empirical Evaluation of the Eurostat MicroAggregation Procedure for the Analysis of the Community Innovation Survey. Technical report.

Jefferson G., B. Huamao, G. Xiaojing and Y. Xiaoyun (2006) R\&D Performance in Chinese Industry. Economics of Innovation and New Technology, 15(4/5). Forthcoming

Levin, R., A. Klevorick, R. Nelson and S. Winter (1987) 'Appropriating the Results of Industrial Research and Development. Brookings Papers on Economic Activity, 1987(3), 783-831.

Maddala, G.S. (1983) Limited-Dependent and Qualitative Variables in Econometrics, Econometric Society Monographs in Quantitative Economics. Cambridge, UK: Cambridge University Press.

Mairesse, J. and P. Mohnen (2001) To Be or Not to Be Innovative: an Exercise in Measurement. OECD STI Review, Special Issue on New Science and Technology Indicators, 27, 103-129.

Mairesse, J. and P. Mohnen (2002) Accounting for Innovation and Measuring Innovativeness: An Illustrative Framework and an Application. American Economic Review, 92 (2) 226-230. 
Mohnen, P. and M. Dagenais (2001) Towards an Innovation Intensity Index: The Case of CIS-1 in Denmark and Ireland. In A. Kleinknecht and P. Mohnen (eds.), Innovation and Firm Performance: Econometric Explorations of Survey Data. Hampshire and New York: Palgrave.

Mohnen, P. and J. Rosa (2002) Barriers to Innovation in Service Industries in Canada. In Maryann Feldman and Nadine Massard (eds.), Institutions and Systems in the Geography of Innovation, Boston, MA: Kluwer Academic Publishers, 231-250.

Neef, D. (ed.) (1998) The Knowledge Economy. Boston: Butterworth-Heinemann.

Organization for Economic Co-operation and Development (1963) The Measurement of Scientific and Technical Activities (Frascati Manual), new edition 1994. Paris: OECD. Organization for Economic Co-operation and Development $(1992,1996)$ Oslo Manual $\left(1^{\text {st }}\right.$ edition 1992, $2^{\text {nd }}$ edition 1996). OECD: Paris

Porter, M. and S. Stern (1999) The New Challenge to America's Prosperity: Findings from an Innovation Index. Washington, DC: Council on Competitiveness.

Puhani, P. (2000) The Heckman Correction for Sample Selection and its Critique. The Journal of Economic Surveys, 14 (1), 53-68.

Quah, D. (2001) The Weightless Economy in Economic Development, in Matti Pohjola (ed.), Information Technology, Productivity, and Economic Growth : International Evidence and Implications for Economic Development. Oxford, UK: Oxford University Press.

Robson, M., J. Townsend and K. Pavitt (1988) Sectoral Patterns of Production and Use of Innovations in the UK: 1945-1983. Research Policy, 17, 1-14. 
Suits, D. (1984) Dummy Variables: Mechanics v. Interpretation. Review of Economics and Statistics, 66,177-180.

Van Leeuwen, G. and L. Klomp (2006) On the Contribution of Innovation to MultiFactor Productivity Growth. Economics of Innovation and New Technology, 15(4/5). Forthcoming.

Wooldridge, J. (2002) Econometrics Analysis of Cross Section and Panel Data. Cambridge, MA: The MIT Press. 
Table 1

Summary statistics: CIS 1 (1992), Micro-aggregated Data

High-tech and Low-tech Industries

\begin{tabular}{|c|c|c|c|c|c|c|c|c|c|}
\hline Variable & & Belgium & Denmark & Germany & Ireland & Italy & $\begin{array}{l}\text { Nether- } \\
\text { lands }\end{array}$ & Norway & $\begin{array}{l}\text { Average } \\
\text { country }\end{array}$ \\
\hline \multirow[t]{2}{*}{ Number of firms } & High-tech (H) & 182 & 223 & 1070 & 259 & 845 & 666 & 150 & 485 \\
\hline & Low-tech (L) & 360 & 349 & 840 & 456 & 1409 & 1012 & 325 & 678 \\
\hline Per cent of "high- & & 33.6 & 39.0 & 56.0 & 36.2 & 37.5 & 40.0 & 31.6 & 41.7 \\
\hline \multicolumn{10}{|l|}{ tech firms" } \\
\hline Average number of & $\mathbf{H}$ & 1164.5 & 301.5 & 1619.7 & 128.7 & 767.0 & 340.2 & 267.5 & 655.6 \\
\hline Employees & $\mathbf{L}$ & 403.0 & 208.0 & 655.9 & 116.8 & 289.5 & 222.5 & 151.6 & 292.5 \\
\hline Per cent employment & & 59.4 & 48.1 & 75.9 & 38.5 & 61.4 & 50.2 & 44.8 & 61.6 \\
\hline \multicolumn{10}{|l|}{ in "high tech firms" } \\
\hline Per cent of firms & $\mathbf{H}$ & 79.7 & 64.6 & 43.5 & 69.1 & 58.5 & 63.7 & 75.3 & 64.9 \\
\hline belonging to a group & $\mathbf{L}$ & 51.4 & 67.0 & 35.2 & 56.1 & 35.7 & 52.9 & 63.7 & 51.7 \\
\hline Percent of innovating & $\mathbf{H}$ & 78.0 & 76.2 & 85.4 & 76.4 & 62.4 & 75.4 & 62.7 & 73.8 \\
\hline firms & $\mathbf{L}$ & 65.3 & 54.2 & 74.6 & 64.0 & 29.2 & 55.9 & 47.1 & 55.8 \\
\hline
\end{tabular}


Table 1 (continued)

\begin{tabular}{|c|c|c|c|c|c|c|c|c|c|}
\hline Variable & & Belgium & Denmark & Germany & Ireland & Italy & $\begin{array}{c}\text { Nether- } \\
\text { lands }\end{array}$ & Norway & $\begin{array}{l}\text { Average } \\
\text { country }\end{array}$ \\
\hline Average share of innovative sales & $\mathbf{H}$ & 48.6 & 48.3 & 51.2 & 46.1 & 41.0 & 44.1 & 48.2 & 46.8 \\
\hline in per cent, for innovating firms & $\mathbf{L}$ & 44.1 & 37.3 & 50.2 & 39.7 & 34.8 & 32.9 & 33.2 & 38.9 \\
\hline Per cent of $R \& D$ doing firms, & $\mathbf{H}$ & 96.5 & 94.7 & 93.1 & 95.5 & 83.3 & 81.9 & 86.2 & 90.2 \\
\hline among innovating firms & $\mathbf{L}$ & 85.1 & 77.2 & 76.7 & 98.3 & 59.2 & 72.3 & 75.2 & 77.7 \\
\hline Average R\&D/sales & $\mathbf{H}$ & 3.6 & 6.1 & 4.9 & 4.0 & 4.2 & 3.6 & 4.1 & 4.4 \\
\hline in per cent, for $R \& D$ doing firms & $\mathbf{L}$ & 1.3 & 2.2 & 3.0 & 2.1 & 2.5 & 1.5 & 1.7 & 2.0 \\
\hline Per cent of firms doing $R \& D$ & $\mathbf{H}$ & 95.6 & 62.7 & 84.3 & 78.3 & 94.1 & 77.1 & 81.5 & 81.9 \\
\hline continuously, of $R \& D$ doing firms & $\mathbf{L}$ & 81.5 & 64.4 & 75.1 & 63.1 & 85.2 & 63.1 & 73.0 & 72.2 \\
\hline Per cent of firms doing coop. & $\mathbf{H}$ & 64.2 & 73.9 & 49.0 & 42.9 & 28.7 & 51.8 & 77.8 & 81.9 \\
\hline R\&D, of R\&D doing firms & $\mathbf{L}$ & 45.0 & 66.4 & 37.8 & 35.9 & 6.6 & 41.8 & 64.3 & 42.5 \\
\hline Per cent of firms with above & $\mathbf{H}$ & 73.1 & 70.4 & 87.7 & 71.8 & 64.5 & 69.2 & 51.3 & 69.7 \\
\hline average perceived competition & $\mathbf{L}$ & 56.9 & 46.4 & 78.0 & 60.5 & 37.4 & 49.4 & 42.8 & 53.1 \\
\hline Per cent of firms with above & $\mathbf{H}$ & 69.2 & 66.8 & 69.5 & 58.7 & 31.4 & 61.7 & 50.0 & 58.2 \\
\hline average proximity to basic rsrch & $\mathbf{L}$ & 47.8 & 43.8 & 51.3 & 47.1 & 14.3 & 42.8 & 40.3 & 41.1 \\
\hline
\end{tabular}




\section{Table 2}

\section{Maximum likelihood Estimates of the Generalized Tobit model of Innovation,}

\section{Pooled across Countries}

\section{High-tech Industries \\ Low-tech Industries}

\begin{tabular}{|c|c|c|c|c|}
\hline Variables & $\begin{array}{c}\text { Propensity to } \\
\text { innovate }\end{array}$ & $\begin{array}{l}\text { Intensity of } \\
\text { innovation }\end{array}$ & $\begin{array}{c}\text { Propensity to } \\
\text { innovate }\end{array}$ & $\begin{array}{l}\text { Intensity of } \\
\text { innovation }\end{array}$ \\
\hline Log of employees & $0.28(.02)$ & $0.21(.03)$ & $0.23(.02)$ & $0.18(.04)$ \\
\hline Indicator for in a group & $0.15(.04)$ & $0.20(.07)$ & $0.24(.03)$ & $0.30(.07)$ \\
\hline R\&D/sales & -- & $1.47(.48)$ & -- & $3.50(.98)$ \\
\hline Indicator for doing R\&D & -- & $0.25(.13)$ & -- & $0.11(.18)$ \\
\hline Doing $R \& D$ on a continuous basis & -- & $0.25(.07)$ & -- & $0.29(.06)$ \\
\hline Doing cooperative $R \& D$ & -- & $0.15(.06)$ & -- & $0.08(.07)$ \\
\hline Perceived competition & -- & $0.51(.07)$ & -- & $0.25(.07)$ \\
\hline Proximity to basic research & -- & $0.36(.06)$ & -- & $0.11(.06)$ \\
\hline Estimated standard error & 1(assumed) & $0.74(.01)$ & 1(assumed) & $0.95(.02)$ \\
\hline
\end{tabular}

Estimated standard errors in parentheses.

Both the probit and Tobit regressions include one set of country indicators and one set of industry indicators (see Table 4). The probit regression also includes a dummy for missing values of the indicator for being part of a group, while the Tobit regression includes this dummy and another one for missing $R \& D /$ sales ratios for $R \& D$ doing firms (see footnote 18). 
Table 3

Estimated Marginal Effects in Percentage Points

for the Generalized Tobit Model of Innovation

\begin{tabular}{|c|c|c|c|c|c|c|}
\hline \multirow{2}{*}{$\begin{array}{l}\text { Variables } \\
\text { Type of firm }\end{array}$} & \multicolumn{2}{|c|}{$\begin{array}{c}\text { Effects on expected } \\
\text { propensity } \\
\text { To innovate }\end{array}$} & \multicolumn{2}{|c|}{$\begin{array}{c}\text { Effects on expected } \\
\text { intensity of innovation } \\
\text { conditional on being } \\
\text { innovative }\end{array}$} & \multicolumn{2}{|c|}{$\begin{array}{c}\text { Effects on expected } \\
\text { intensity of innovation } \\
\text { unconditional on being } \\
\text { innovative }\end{array}$} \\
\hline & $\mathbf{H}$ & $\mathbf{L}$ & $\mathbf{H}$ & $\mathbf{L}$ & $\mathbf{H}$ & $\mathbf{L}$ \\
\hline Log employees & 8.8 & 9.0 & -0.6 & -2.2 & 3.3 & 2.3 \\
\hline Part of a group & 4.8 & 9.8 & 1.3 & -0.6 & 3.0 & 3.4 \\
\hline R\&D/sales & -- & -- & 24.6 & 54.5 & 18.4 & 29.4 \\
\hline Doing R\&D & -- & -- & 4.2 & 1.7 & 3.2 & 0.9 \\
\hline Doing $R \& D$ continuously & -- & -- & 4.3 & 4.6 & 3.2 & 2.5 \\
\hline Doing cooperative $R \& D$ & -- & -- & 2.5 & 1.3 & 1.9 & 0.7 \\
\hline Perceived competition & -- & -- & 8.5 & 3.9 & 6.3 & 2.1 \\
\hline $\begin{array}{l}\text { Proximity to basic } \\
\text { research }\end{array}$ & -- & -- & 6.1 & 1.7 & 4.5 & 0.9 \\
\hline Countries & & & & & & \\
\hline Belgium & -3.1 & 9.1 & 4.9 & 9.2 & 2.1 & 9.3 \\
\hline Denmark & 0.1 & -2.0 & 3.5 & 5.0 & 2.7 & 1.7 \\
\hline Germany & 10.1 & 17.4 & -2.1 & 9.6 & 2.8 & 13.7 \\
\hline Ireland & 5.9 & 13.1 & 2.7 & 1.4 & 4.9 & 6.2 \\
\hline Italy & -17.3 & -35.7 & -7.2 & -11.1 & -11.7 & -16.0 \\
\hline Netherlands & 3.9 & 0.9 & -2.9 & -6.7 & -0.5 & -3.1 \\
\hline
\end{tabular}




\begin{tabular}{|c|c|c|c|c|c|c|}
\hline Norway & -4.3 & -0.5 & 3.4 & -2.1 & 0.4 & -1.3 \\
\hline \multicolumn{7}{|l|}{ Manufacturing Industries } \\
\hline Vehicles & -6.4 & -- & -0.5 & -- & -3.2 & -- \\
\hline Chemical & -4.0 & -- & -10.1 & -- & -8.7 & -- \\
\hline Machinery \& Equipment & 2.2 & -- & 4.7 & -- & 4.6 & -- \\
\hline Electrical & 3.8 & -- & 2.9 & -- & 4.1 & -- \\
\hline Food & -- & 0.7 & -- & 0.8 & -- & 0.8 \\
\hline Textile & -- & -1.4 & -- & 6.1 & -- & 2.7 \\
\hline Wood & -- & -7.7 & -- & -3.1 & -- & -4.3 \\
\hline Plastic & -- & 11.0 & -- & 0.5 & -- & 4.9 \\
\hline Non-Metallic & -- & 3.7 & -- & -5.4 & -- & -1.4 \\
\hline Metals & -- & 0.7 & -- & -3.5 & -- & -1.5 \\
\hline NEC & -- & 3.7 & -- & 7.5 & -- & 5.8 \\
\hline
\end{tabular}

H: High-tech industries; L: Low-tech industries.

The table shows the estimated marginal effects (in percentage points) for the generalized Tobit model of innovation at the European means of the explanatory variables, with equal country weights and average European industry structure. See Table 2 for the estimated model parameters. 
Table 4

Accounting for Inter-Country Differences in Innovation

A) Propensity to Innovate

\begin{tabular}{|c|c|c|c|c|c|c|c|}
\hline \multirow[t]{2}{*}{ Source: } & \multirow{2}{*}{$\begin{array}{l}\text { European } \\
\text { propensity }\end{array}$} & \multirow[b]{2}{*}{ Industry effects } & \multirow{2}{*}{$\begin{array}{c}\text { Size and group } \\
\text { effects }\end{array}$} & \multirow{2}{*}{$\begin{array}{c}\text { Sum of } \\
\text { structural effects }\end{array}$} & \multirow{2}{*}{$\begin{array}{l}\text { Expected } \\
\text { propensity }\end{array}$} & \multirow{2}{*}{$\begin{array}{l}\text { Propensity } \\
\text { innovativity }\end{array}$} & \multirow{2}{*}{$\begin{array}{l}\text { Observed } \\
\text { propensity }\end{array}$} \\
\hline & & & & & & & \\
\hline & \multicolumn{7}{|c|}{ High-tech Industries } \\
\hline Belgium & 73.8 & -0.3 & 6.2 & 5.9 & 79.7 & -1.7 & 78.0 \\
\hline Denmark & 73.8 & 0.8 & -1.7 & -0.9 & 72.9 & 3.3 & 76.2 \\
\hline Germany & 73.8 & 0.8 & 2.3 & 3.1 & 76.9 & 8.5 & 85.4 \\
\hline Ireland & 73.8 & 0.5 & -6.0 & -5.5 & 68.3 & 8.1 & 76.4 \\
\hline Italy & 73.8 & 0.2 & 3.0 & 3.2 & 77.0 & -14.6 & 62.4 \\
\hline Netherlands & 73.8 & -0.4 & -2.9 & -3.3 & 70.5 & 4.9 & 75.4 \\
\hline Norway & 73.8 & -1.6 & -0.9 & -2.5 & 71.3 & -8.6 & 62.7 \\
\hline Average country & 73.8 & 0.0 & 0.0 & 0.0 & 73.8 & 0.0 & 73.8 \\
\hline
\end{tabular}




\begin{tabular}{|c|c|c|c|c|c|c|c|}
\hline \multirow[b]{2}{*}{ Belgium } & \multicolumn{7}{|c|}{ Low-tech Industries } \\
\hline & 55.8 & 0.0 & 1.0 & 1.0 & 56.8 & 8.5 & 65.3 \\
\hline Denmark & 55.8 & 0.4 & 2.4 & 2.8 & 58.6 & -4.4 & 54.2 \\
\hline Germany & 55.8 & 1.4 & 2.3 & 3.7 & 59.5 & 15.1 & 74.6 \\
\hline Ireland & 55.8 & 0.5 & -3.7 & -3.2 & 52.6 & 11.4 & 64.0 \\
\hline Italy & 55.8 & 0.2 & 0.1 & 0.3 & 56.1 & -26.9 & 29.2 \\
\hline Netherlands & 55.8 & -1.4 & -0.8 & -2.2 & 53.6 & 2.3 & 55.9 \\
\hline Norway & 55.8 & -1.2 & -1.2 & -2.4 & 53.4 & -6.3 & 47.1 \\
\hline Average country & 55.8 & 0.0 & 0.0 & 0.0 & 55.8 & 0.0 & 55.8 \\
\hline
\end{tabular}

Small discrepancies are due to rounding. 
B) Intensity of Innovation Conditionally on Being Innovative

\begin{tabular}{|c|c|c|c|c|c|c|c|c|c|}
\hline Source: & $\begin{array}{l}\text { European } \\
\text { intensity }\end{array}$ & $\begin{array}{l}\text { Industry } \\
\text { effects }\end{array}$ & $\begin{array}{c}\text { Size } \\
\text { and Group } \\
\text { effects }\end{array}$ & R\&D effects & $\begin{array}{l}\text { Environ- } \\
\text { ment } \\
\text { effects }\end{array}$ & $\begin{array}{c}\text { Sum of } \\
\text { structural } \\
\text { effects }\end{array}$ & $\begin{array}{l}\text { Expected } \\
\text { intensity }\end{array}$ & $\begin{array}{l}\text { Conditional } \\
\text { innovativity }\end{array}$ & $\begin{array}{l}\text { Observed } \\
\text { intensity }\end{array}$ \\
\hline & \multicolumn{9}{|c|}{ High-tech Industries } \\
\hline Belgium & 46.8 & -1.4 & -0.2 & 1.1 & 0.7 & 0.2 & 47.0 & -0.2 & 48.6 \\
\hline Denmark & 46.8 & 1.1 & 0.1 & 0.4 & 0.6 & 2.3 & 49.1 & -0.8 & 48.3 \\
\hline Germany & 46.8 & 1.4 & -0.5 & 0.3 & 0.8 & 1.9 & 48.7 & 2.5 & 51.2 \\
\hline Ireland & 46.8 & -0.9 & 0.5 & -0.4 & -0.5 & -1.2 & 45.6 & 0.5 & 46.1 \\
\hline Italy & 46.8 & 0.2 & -0.4 & -0.5 & -1.2 & -1.9 & 44.9 & -3.9 & 41.0 \\
\hline Netherlands & 46.8 & -0.8 & 0.2 & -1.0 & 0.1 & -1.5 & 45.3 & -1.2 & 44.1 \\
\hline Norway & 46.8 & 0.4 & 0.2 & 0.1 & -0.5 & 0.2 & 47.0 & 1.2 & 48.2 \\
\hline $\begin{array}{l}\text { Average } \\
\text { country }\end{array}$ & 46.8 & 0.0 & 0.0 & 0.0 & 0.0 & 0.0 & 46.8 & 0.0 & 46.8 \\
\hline
\end{tabular}




\begin{tabular}{|c|c|c|c|c|c|c|c|c|c|}
\hline \multirow[b]{2}{*}{ Belgium } & \multicolumn{9}{|c|}{ Low-tech Industries } \\
\hline & 38.9 & 0.8 & -0.4 & 0.3 & 0.1 & 0.8 & 39.7 & 4.4 & 44.1 \\
\hline Denmark & 38.9 & -0.6 & -0.1 & 0.1 & -0.1 & -0.7 & 38.2 & -0.9 & 37.3 \\
\hline Germany & 38.9 & -0.4 & -0.6 & 0.4 & 0.4 & -0.2 & 38.7 & 11.5 & 50.2 \\
\hline Ireland & 38.9 & 0.9 & 1.3 & 0.0 & -0.1 & 2.1 & 41.0 & -1.3 & 39.7 \\
\hline Italy & 38.9 & 0.5 & -0.9 & -0.3 & -0.2 & -0.9 & 38.0 & -3.2 & 34.8 \\
\hline Netherlands & 38.9 & -1.1 & 0.2 & -0.6 & -0.1 & -1.5 & 37.4 & -4.5 & 32.9 \\
\hline Norway & 38.9 & -0.2 & 0.5 & 0.1 & 0.0 & 0.4 & 39.3 & -6.1 & 33.2 \\
\hline \multicolumn{10}{|l|}{ Average } \\
\hline country & 38.9 & 0.0 & 0.0 & 0.0 & 0.0 & 0.0 & 38.9 & 0.0 & 38.9 \\
\hline
\end{tabular}

Small discrepancies are due to rounding. 
C) Intensity of Innovation Unconditionally on Being Innovative

\begin{tabular}{|c|c|c|c|c|c|c|c|c|c|}
\hline \multirow{3}{*}{ Source: } & & & Size & & & Sum of & & & \multirow{3}{*}{$\begin{array}{c}\text { Observed } \\
\text { intensity }\end{array}$} \\
\hline & European & Industry & and Group & & Environ- & structural & Expected & & \\
\hline & intensity & effects & effects & $R \& D$ effects & ment effects & effects & intensity & Innovativity & \\
\hline & \multicolumn{9}{|c|}{ High-tech Industries } \\
\hline Belgium & 34.7 & -1.2 & 2.6 & 0.9 & 0.7 & 3.0 & 37.7 & 0.2 & 37.9 \\
\hline Denmark & 34.7 & 1.3 & -0.7 & 0.4 & 0.4 & 1.4 & 36.1 & 0.7 & 36.8 \\
\hline Germany & 34.7 & 1.3 & 0.6 & 0.9 & 1.7 & 4.5 & 39.2 & 4.6 & 43.8 \\
\hline Ireland & 34.7 & -0.6 & -2.2 & 0.1 & -0.1 & -2.6 & 32.1 & 3.1 & 35.2 \\
\hline Italy & 34.7 & 0.4 & 1.1 & -0.9 & -1.6 & -1.0 & 33.7 & -8.1 & 25.6 \\
\hline Netherlands & 34.7 & -0.8 & -1.1 & -0.6 & 0.1 & -2.4 & 32.3 & 1.0 & 33.3 \\
\hline Norway & 34.7 & -0.5 & -0.2 & -0.7 & -1.5 & -2.9 & 31.8 & -1.6 & 30.2 \\
\hline Average & 34.7 & 0.0 & 0.0 & 0.0 & 0.0 & 0.0 & 34.7 & 0.0 & 34.7 \\
\hline
\end{tabular}




\begin{tabular}{|c|c|c|c|c|c|c|c|c|c|}
\hline \multirow[b]{2}{*}{ Belgium } & \multicolumn{9}{|c|}{ Low-tech Industries } \\
\hline & 22.3 & 0.4 & 0.3 & 0.2 & 0.1 & 1.0 & 23.3 & 5.5 & 28.8 \\
\hline Denmark & 22.3 & 0.0 & 0.7 & 0.0 & -0.1 & 0.6 & 22.9 & -2.7 & 20.2 \\
\hline Germany & 22.3 & 0.3 & 0.4 & 0.4 & 0.6 & 1.7 & 24.0 & 13.5 & 37.5 \\
\hline Ireland & 22.3 & 0.4 & -0.9 & 0.2 & 0.2 & -0.1 & 22.2 & 3.3 & 25.5 \\
\hline Italy & 22.3 & 0.7 & -0.1 & -0.4 & -0.6 & -0.4 & 21.9 & -11.7 & 10.2 \\
\hline Netherlands & 22.3 & -1.0 & -0.2 & -0.2 & -0.1 & -1.5 & 20.8 & -2.4 & 18.4 \\
\hline Norway & 22.3 & -0.8 & -0.2 & -0.1 & -0.2 & -1.3 & 21.0 & -5.4 & 15.6 \\
\hline $\begin{array}{l}\text { Average } \\
\text { country }\end{array}$ & 22.3 & 0.0 & 0.0 & 0.0 & 0.0 & 0.0 & 22.3 & 0.0 & 22.3 \\
\hline
\end{tabular}

Small discrepancies are due to rounding errors. 


\section{APPENDIX A: Accounting for Innovation and Measuring Innovativity}

Assume for simplicity that there are only two countries (A and B) and two industries (1 and 2). The expected intensity of innovation, whether unconditional or conditional on being innovative, that is equations (5) or (6), can be written as (ignoring the firm subscripts to ease notation):

$$
y=f(C, Z)=f\left(\alpha_{1}+\alpha_{2} C_{B}+\beta_{2} I_{2}, Z\right)
$$

where we have taken country A and industry 1 for reference in expressing the general country and industry specific constant $\mathrm{C}$, with $C_{B}$ being the dummy for country $\mathrm{B}$ and $I_{2}$ the dummy for industry 2, and where $\mathrm{Z}$ stands for a set of other explanatory variables (or innovation factors). Note that the function $f$ could as well represent the expected probability to innovate, that is, equation (4). Note also that we could have made a different choice of normalization (so that for example the two countries and the two industries be treated symmetrically); our final innovation accounting decomposition in terms of structural effects and innovativity, as shown in Table A1, does not depend on it.

Let $y^{A}, y^{B}$, and $y^{E}$ be the respective mean values of the observed intensity of innovation for country A, country B and the average country of reference (say the hypothetical average European country), and let $y^{* A}, y^{* B}$, and $y^{{ }^{* E}}$ represent the corresponding expected intensity of innovation taken at respectively the mean values of the explanatory variables for these three countries. Assuming for simplicity that we have the same number of observations for the two countries (or giving them equal weight as we have done in our analysis), we have respectively

$$
\begin{aligned}
& y^{A}=y^{{ }^{* A}}+e^{{ }^{*} A}=f\left(\alpha_{1}+w_{2}^{A} \beta_{2}, Z^{A}\right)+e^{{ }^{*} A} \\
& y^{B}=y^{{ }^{*}}+e^{{ }^{B}}=f\left(\alpha_{1}+\alpha_{2}+w_{2}^{B} \beta_{2}, Z^{B}\right)+e^{{ }^{B} B} \\
& y^{E}=y^{{ }^{*} E}+e^{{ }^{*} E}=f\left(\alpha_{1}+\alpha_{2} / 2+w_{2}^{E} \beta_{2}, Z^{E}\right)+e^{{ }^{*} E}
\end{aligned}
$$

where $w_{2}^{E}=\left(w_{2}^{A}+w_{2}^{B}\right) / 2$ is the average proportion of firms in industry 2 in the two countries, $Z^{E}=\left(Z^{A}+Z^{B}\right) / 2$ is the average value of $\mathrm{Z}$ in the two countries, and $e^{{ }^{A} A}, e^{{ }^{B} B}$, and $e^{{ }^{*} E}$ are approximation errors due to the fact that the expected innovation intensity functions $f($.$) are not$ linear. Going one step further, by considering a linear approximation of $y^{{ }^{* A}}$ and $y^{* B}$ around $y^{* E}$ (i.e., in deviation to the mean values of the explanatory variables for the country of reference), we can write the two following innovation accounting equations:

$$
y^{A}=y^{E}+f_{C}^{E} \beta_{2}\left(w_{2}^{A}-w_{2}^{E}\right)+f_{Z}^{E}\left(Z^{A}-Z^{E}\right)+f_{C}^{E}\left(-\alpha_{2} / 2\right)+e^{A}+\left(e^{*^{A}}-e^{{ }^{E}}\right)
$$




$$
y^{B}=y^{E}+f_{C}^{E} \beta_{2}\left(w_{2}^{B}-w_{2}^{E}\right)+f_{Z}^{E}\left(Z^{B}-Z^{E}\right)+f_{C}^{E}\left(\alpha_{2} / 2\right)+e^{B}+\left(e^{* B}-e^{* E}\right)
$$

where $f_{x}^{E}$ represents the gradient of $f($.$) with respect to \mathrm{C}$ and $\mathrm{Z}$ evaluated at the country of reference average values for $\mathrm{C}$ and $\mathrm{Z}$, and $e^{A}$ and $e^{B}$ are first-order approximation errors. Notice that $e^{E}=\left(e^{A}+e^{B}\right) / 2=0$.

The first term of these approximations is the innovation intensity of the average country of reference. The second and third terms are the deviations from this value of reference (for country A or B) which are respectively accounted for by the industry effects and the explanatory variables Z, these two terms summing to what we can label as "structural effects. The last three terms, the country effect, the first-order approximation error and the non-linearity discrepancy, capture what we call innovativity, the difference between the observed innovation intensity and the approximate expected innovation intensity, practically computed as the sum of three first terms. If the function $f($.$) was linear, the last two terms would be nil and innovativity will be nothing but the country$ effect. $^{28}$

The following Table A1 summarizes the resulting decomposition of the country differences in innovation relative to the average country in terms of the structural effects of the various factors of innovation taken into account in the analysis and of innovativity. It allows for an easy bilateral comparison of the innovation performance of the couple of countries considered, or a multilateral comparison when more than two countries are considered.

\footnotetext{
${ }^{28}$ Note that we could have performed a similar decomposition without making a linear approximation. We could have computed the effects of each explanatory variable sequentially, by starting from the value of innovation intensity taken at the means of all explanatory variables for the country of reference, and replacing them one by one by their respective country means. In this case, however, the size of the effects of the different variables would not be independent of the order of the sequence. One advantage of the linear approximation, besides being quite straightforward, is that the order in which we examine the separate structural effects makes no difference.
} 
Table A1: Accounting for inter-country differences in innovation

relative to the average country

\begin{tabular}{|c|c|c|c|c|c|c|c|}
\hline & $\begin{array}{l}\text { Average } \\
\text { country of } \\
\text { reference } \\
\text { (1) }\end{array}$ & Industry effects & $\begin{array}{l}\text { Effects of } \\
\text { variable Z }\end{array}$ & $\begin{array}{c}\text { Total of } \\
\text { structural } \\
\text { effects } \\
\text { (4) }\end{array}$ & $\begin{array}{l}\text { Expected } \\
\text { innovation }\end{array}$ & $(6)=(7)-(5)$ & $\begin{array}{l}\text { Observed } \\
\text { innovation }\end{array}$ \\
\hline Country A & $y^{E}$ & $f_{C}^{E} \beta_{2}\left(w_{2}^{A}-w_{2}^{E}\right)$ & $f_{Z}^{E}\left(Z^{A}-Z^{E}\right)$ & $(2)+(3)$ & $(1)+(4)$ & $f_{C}^{E}\left(-\alpha_{2} / 2\right)+e^{A}$ & $y^{A}$ \\
\hline Country B & $y^{E}$ & $f_{C}^{E} \beta_{2}\left(w_{2}^{B}-w_{2}^{E}\right)$ & $f_{Z}^{E}\left(Z^{B}-Z^{E}\right)$ & $(2)+(3)$ & $(1)+(4)$ & $f_{C}^{E}\left(\alpha_{2} / 2\right)+e^{B}$ & $y^{B}$ \\
\hline Average & $y^{E}$ & 0 & 0 & 0 & $y^{E}$ & 0 & $y^{E}$ \\
\hline Country & & & & & & & \\
\hline
\end{tabular}




\section{APPENDIX B: Industry Definition and Composition}

Table B1: Definition of Industries

\begin{tabular}{|c|c|c|}
\hline INDUSTRY & NACE CODE & INDUSTRY DESCRIPTION \\
\hline \multicolumn{3}{|r|}{ High-tech Sectors } \\
\hline Vehicles & $34-35$ & Manufacture of motor vehicles, trailers, semi-trailers, and other transport equipment \\
\hline Chemicals & $23-24$ & Manufacture of coke, refined petroleum products and nuclear fuel, manufacture of chemicals and chemical products \\
\hline Machinery & 29 & Manufacture of machinery and equipment NEC \\
\hline Electrical & $30-33$ & $\begin{array}{l}\text { Manufacture of office machinery and computers, electrical machinery; Apparatus, radio, television and communication } \\
\text { equipment; Apparatus, medical, precision and optical instruments, watches and clocks }\end{array}$ \\
\hline \multicolumn{3}{|r|}{ Low-tech Sectors } \\
\hline Food & $15-16$ & Manufacture of food, beverages and tobacco \\
\hline Textile & $17-19$ & $\begin{array}{l}\text { Manufacture of textiles, wearing apparel, dressing and dyeing of fur, tannings, and dressing of leather, luggage, handbags, } \\
\text { saddlery, harness and footwear }\end{array}$ \\
\hline Wood & $20-22$ & $\begin{array}{l}\text { Manufacture of wood and products of wood and cork, except furniture, manufacture of straw and plaiting materials, pulp, } \\
\text { paper, and paper products, publishing, printing, and reproduction of recorded media }\end{array}$ \\
\hline Plastic rubber & 25 & Manufacture of rubber and plastic products \\
\hline Non-metallic & 26 & Manufacture of other non-metallic mineral products \\
\hline Basic metal & $27-28$ & Manufacture of basic metals, fabricated metal products, except machinery and equipment \\
\hline NEC & 36 & Manufacture of furniture, manufacturing Non Elsewhere Classified \\
\hline
\end{tabular}

${ }^{\mathrm{a}}$ Revision 1. 
Table B2: Industry Composition by Country (in \% of numbers of firms)

\begin{tabular}{|c|c|c|c|c|c|c|c|c|}
\hline INDUSTRY & Belgium & Denmark & Germany & Ireland & $\begin{array}{l}\text { Nether- } \\
\text { lands }\end{array}$ & Norway & Italy & $\begin{array}{l}\text { Average } \\
\text { country }\end{array}$ \\
\hline \multicolumn{9}{|c|}{ High-tech Industries } \\
\hline VEHICLES & 12.6 & 12.5 & 11.9 & 6.6 & 13.7 & 42.0 & 15.1 & 16.3 \\
\hline CHEMICAL & 33.0 & 15.3 & 15.2 & 32.0 & 30.1 & 12.0 & 20.6 & 22.6 \\
\hline MACH\&EQ & 25.8 & 43.5 & 43.6 & 19.3 & 36.2 & 27.3 & 37.3 & 33.2 \\
\hline ELEC & 28.6 & 28.7 & 29.3 & 42.1 & 20.0 & 18.7 & 27.0 & 27.9 \\
\hline \multicolumn{9}{|c|}{ Low-tech Industries } \\
\hline FOOD & 18.3 & 22.3 & 10.8 & 25.0 & 17.8 & 27.4 & 13.0 & 19.2 \\
\hline TEXTILE & 23.9 & 7.2 & 10.8 & 15.1 & 9.9 & 6.5 & 30.1 & 14.8 \\
\hline WOOD & 16.1 & 20.3 & 13.5 & 18.7 & 28.1 & 29.5 & 11.9 & 19.7 \\
\hline PLASTIC & 5.3 & 9.2 & 14.6 & 11.6 & 0.3 & 2.8 & 4.8 & 6.9 \\
\hline NONMET & 10.0 & 8.0 & 9.3 & 6.8 & 7.8 & 5.8 & 11.2 & 8.5 \\
\hline METAL & 17.0 & 22.7 & 32.5 & 15.1 & 29.0 & 19.7 & 19.7 & 22.2 \\
\hline NEC & 9.4 & 10.3 & 8.5 & 7.7 & 7.1 & 8.3 & 9.3 & 8.7 \\
\hline
\end{tabular}

